\title{
Attack during time-out from a fixed-interval schedule in pigeons
}

\author{
THOMAS A. LOONEY \\ Lynchburg College, Lynchburg, Virginia 24501
}

\begin{abstract}
Deweese (1977) reported that when a time-out followed food delivery on a fixed-interval 180 -sec schedule, squirrel monkeys did not attack until after the time-out. A similar procedure was employed with pigeons in the present study, with different results. It was demonstrated that the time-out stimulus exerted control over food-key responses but did not attenuate attack. In addition, when subjects were subsequently allowed to initiate time-outs, responding on the time-out key was not maintained. The results of the present study support the conclusion that the time-out stimulus was aversive.
\end{abstract}

A variety of species exhibit aggression when exposed to intermittent schedules of positive reinforcement (see Looney \& Cohen, 1982, for a general review as well as for specific comments related to the following discussion). Food-deprived subjects usually attack a target soon after food removal; however, a notable exception to this general finding was reported by DeWeese (1977). In her study of squirrel monkeys, a 10-sec timeout was initially imposed following food delivered on fixed-interval (FI) schedules with intervals ranging from 6 to $600 \mathrm{sec}$. The chamber was illuminated by a red light during each FI cycle and by a green light during time-outs that intervened between FI cycles. A few attacks to the bite-hose target occurred during timeouts following food presentation under FI 6-, 20 -, and 60 -sec schedules, but not at longer intervals.

In an experiment using an FI 180-sec food schedule, DeWeese (1977) varied the time-out duration over a range of $0-100 \mathrm{sec}$ and found that no consistent changes occurred in the number of bites during time-out. In each case, hose biting began at the start of the FI cycle, thus suggesting to DeWeese that the attack was not induced by food withdrawal.

The question arises as to why attack did not occur during the time-out from the FI 180-sec schedule. One possibility is suggested by the findings of Ator (1980) and Brown (Note 1), who found that when given concurrent access to time-outs and a target, 9 of 10 pigeons that attacked the target did not do so during subjectimposed time-outs. Brown suggested that time-outs remove the aversive stimuli that engender attack. If this is the case, it is possible that this would also be true with an experimenter-imposed time-out. It is unclear, however, why the time-out used in the DeWeese (1977) study did not itself eventually become aversive, since each presentation immediately followed

This research was supported in part by USPHS Grant R03MH 31172-01 to Lynchburg College. The author thanks M. A. Looney, P. S. Cohen, and E. F. Segal for their helpful comments. reinforcement. The time-out was thus a signaled extinction period that was removed from food by a minimum of $180 \mathrm{sec}$ (see Azrin, Hutchinson, \& Hake, 1966).

Because of the importance of DeWeese's (1977) findings for theories of induced attack (Looney \& Cohen, 1982), the present experiment investigated this phenomenon with pigeons. The general strategy employed was to demonstrate that operant responding was under the control of the experimenter-imposed time-out, to determine whether attack would occur during this time-out, and finally, to determine whether subjects would respond to produce time-outs as has been found by others (e.g., Ator, 1980; Brown \& Flory, 1972; Brown, Note 1).

\section{METHOD}

Subjects

Six experimentally naive 5-year-old male White King pigeons from Palmetto Pigeon Plant (Sumter, South Carolina) were maintained at approximately $75 \%$ of their free-feeding body weights. They were visually isolated from each other in individual home cages under $16 \mathrm{~h}$ of light followed by $8 \mathrm{~h}$ of darkness. Water and health grit were continuously available. Wing and tail feathers were periodically trimmed.

\section{Apparatus}

A black operant pigeon chamber $(35.6 \times 35.6 \times 34.3 \mathrm{~cm}$ high) with a black, three-key intelligence panel was employed. One of the keys was covered throughout the experiment. The other keys could be illuminated with either red or green light. The food hopper could be made available through a $5.0 \times 5.7 \mathrm{~cm}$ opening centered on the intelligence panel $8.9 \mathrm{~cm}$ above the floor.

During parts of the experiment, a pictorial target was presented. This was a color photograph of a conspecific, very similar in appearance to Pictorial Target B employed by Looney, Cohen, and Yoburn (1976). It was mounted on a recording screen located behind an $11.4 \times 15.2 \mathrm{~cm}$ high opening centered on the rear wall $8.9 \mathrm{~cm}$ from the floor. To prevent damage to the photograph, it was covered with Con-Tact brand transparent selfadhesive plastic. An attack was recorded when a force of at least $.1 \mathrm{~N}$ was applied to the target. Chamber illumination was provided by a $24-\mathrm{V}$ houselight mounted above the center key and protected by a clear plastic covering. A blower provided 
ventilation and masked extraneous sounds. Experimental conditions and recordings were controlled by standard electromechanical devices.

\section{Procedure}

Initial training and the first test of control by the time-out stimulus. During the first session, subjects were trained to eat reliably from the food hopper and to peck the center key, which was illuminated green for three subjects and red for the others. Each of the first 10 pecks was reinforced with a $10-\mathrm{sec}$ food presentation. In subsequent sessions, the first response to the center key was reinforced, and, thereafter, responses were reinforced on an FI schedule. Sessions terminated immediately following the 13th 10-sec hopper presentation.

Except where noted, the first 12 food presentations were immediately followed by a 10 -sec experimenter-imposed timeout, during which the key light was changed to the alternate color (red or green) not used as the S+ (i.e., the signal for the FI schedule). During time-out, keypecks were recorded but had no other scheduled consequence. Following the time-out, the $\mathrm{S}+$ was presented and the FI schedule was again in effect. Four sessions with an FI 10 -sec schedule were followed by a single session in which reinforcement was scheduled on an FI 20-sec schedule and no time-outs were presented. The previous timeout/FI 10-sec sequence was reinstated in the following session.

Continued FI training and target presentation. Food was scheduled on an FI 30-sec schedule for three sessions, FI $90 \mathrm{sec}$ for three sessions, and then FI $180 \mathrm{sec}$. For the remainder of the experiment, the minimum interfood interval was always 190 sec. After 10 sessions with an FI 180 -sec schedule, the pictorial target was presented, and during the next 10 sessions, timeouts occurred as usual, followed by five sessions with the timeout removed and five sessions with the time-out reinstated. During the following session, in which no time-out was presented, key and attack responses were recorded in the period 60 to $70 \mathrm{sec}$ postfood. When time-outs were reinstated in the next session, they began $60 \mathrm{sec}$ postfood. This was followed by another session with no time-outs.

Availability of subject-imposed time-outs. During the remainder of the experiment, the target was removed and an FI 190-sec schedule was in effect. Beginning with the second session, a second key was illuminated the same color as the S+. A response on this key changed both key lights to the time-out color for $10 \mathrm{sec}$. During a subject-imposed time-out, responses were recorded but had no other scheduled consequence. During the 10 days of this condition, no experimenter-imposed time-outs were scheduled.

\section{RESULTS}

\section{Initial Training and the First Test of \\ Control by the Time-Out Stimulus}

Very quickly, the time-out stimulus came to control operant responding. This is demonstrated in a comparison of responding that occurred during the first $10 \mathrm{sec}$ following reinforcement under the time-out/FI 10-sec condition with the responding under the FI 20-sec schedule condition. The best control was seen with a subject that made 0,46 , and 0 responses during the $10 \mathrm{sec}$ following food removal in the time-out, FI 20 -sec, and time-out conditions, respectively. Stimulus control was poorest for a subject that made 15,65 , and 20 responses in these three sessions.

\section{Continued FI Training and Target Presentation}

Five of the six subjects showed sustained attack throughout the experiment (cf. Looney \& McClure,
Table 1

Average Number of Attacks per Minute in the $10 \mathrm{Sec}$ Immediately Following Food Removal During Either Time-Out (TO) or S+

\begin{tabular}{|c|c|c|c|c|c|c|}
\hline \multirow{3}{*}{$\begin{array}{c}\text { Condi- } \\
\text { tion }\end{array}$} & \multicolumn{6}{|c|}{ Subject } \\
\hline & \multicolumn{3}{|c|}{ Green S+ } & \multicolumn{3}{|c|}{ Red S+ } \\
\hline & 8525 & 9020 & 207 & 9098 & 8592 & 9004 \\
\hline TO & 12.4 & 0 & 25.0 & 15.3 & 71.2 & 14.3 \\
\hline$S+$ & 12.3 & 0 & 77.7 & 16.5 & 57.5 & 20.0 \\
\hline TO & 11.5 & 0 & 107.0 & 21.2 & 59.2 & 15.3 \\
\hline
\end{tabular}

Note-Averages are based on the last three sessions of each condition.

Table 2

Total Number of Attacks and Key Responses During the Test Period 60-70 Sec Following Food Removal During Either Time-Out (TO) or S+

\begin{tabular}{crrrrrrr}
\hline & & \multicolumn{7}{c}{ Subject } \\
\cline { 3 - 7 } $\begin{array}{c}\text { Condi- } \\
\text { tion }\end{array}$ & & 8525 & 9020 & 207 & 9098 & 8592 & 9004 \\
\hline \multirow{2}{*}{ S+ } & K & 34 & 28 & 66 & 109 & 7 & 77 \\
& $\mathrm{~A}$ & 4 & 0 & 48 & 2 & 36 & 6 \\
\multirow{2}{*}{ TO } & $\mathrm{K}$ & 3 & 1 & 2 & 15 & 0 & 13 \\
& $\mathrm{~A}$ & 12 & 0 & 65 & 7 & 38 & 13 \\
& $\mathrm{~K}$ & 28 & 26 & 93 & 137 & 17 & 65 \\
$\mathrm{~S}+$ & $\mathrm{A}$ & 1 & 0 & 34 & 3 & 26 & 10 \\
\hline
\end{tabular}

Note $-K=$ key response A = attack.

1981). To determine whether time-outs attenuated attack, the rate of attack in the $10 \mathrm{sec}$ following food was compared under time-out and S+ conditions. Table 1 shows attack rate was not reliably different under the two conditions. In contrast, Table 2 reveals that keypecks decreased and attacks increased when a time-out replaced the $\mathrm{S}+60 \mathrm{sec}$ following food removal.

\section{Availability of Subject-Imposed Time-Outs}

Within the first five sessions of this condition, all six subjects pecked the key that produced the time-out stimulus. For five of the subjects, responses ranged from five to nine during the session in which contact with the key was first made. In contrast, the remaining subject (8592) imposed 85 time-outs in the first session, but made zero responses in each of the last five sessions. The median number of imposed time-outs in the last five sessions was zero for the remaining subjects as well.

\section{DISCUSSION}

The data can be summarized as follows: (1) The time-out stimulus exerted control over food-key responses; (2) the timeout stimulus did not attenuate attack; and (3) subject-initiated time-outs were not sufficiently reinforcing to maintain responding.

Difference between these results and those reported in other studies of pigeons may be due to a variety of factors. Ator (1980) and Brown (Note 1) found that attacks virtually never occurred during subject-imposed time-outs. Brown suggested that time-outs removed the aversive stimuli that engender attack. It is possible that, in the present study, repeated exposure to 
experimenter-imposed time-out resulted in that stimulus becoming at least as aversive as is the S+following food removal.

Another possibility has been suggested by Ator (1980). She reported that attack most frequently occurred immediately after food removal, whereas time-outs generally occurred late in the postreinforcement pause. These same patterns have also been reported in other studies of either attack (e.g., Cohen \& Looney, 1973; Flory, 1969) or subject-imposed time-outs (e.g., Azrin, 1961). Ator also noted that the overall rate of attack did not change systematically when both the target and the time-out key were available vs. only the target. Thus, it appears that subjectimposed time-outs did not attenuate attack. Rather, they simply occurred when attack was unlikely. In contrast, in the present experiment, experimenter-imposed time-outs were generally presented when attack was very probable. Attack that began with food removal continued well into the interreinforcement interval. So, it is not surprising that attacks occurred during the time-outs imposed $60 \mathrm{sec}$ after food removal.

In the present study, subject-imposed time-outs were not maintained. This is not surprising, since the time-out stimulus should have become aversive during the experimenter-imposed presentations. It should be noted, however, that similar timeout stimuli have not always maintained responding, even when time-out imposition was always under the control of the subject throughout the experiment (e.g., Coughlin, 1972; Zimmerman \& Ferster, 1974).

It is unclear how to reconcile the results of the present study with the data reported by DeWeese (1977), who also imposed a time-out following food removal. The fact that attack failed to occur in time-outs of up to $100 \mathrm{sec}$ in her study of squirrel monkeys does not seem consistent with current accounts of schedule-induced attack (Looney \& Cohen, 1982). It should be noted that most conceptualizations of induced attack are based primarily on experiments with pigeons, thus emphasizing the need for additional studies with other species.

\section{REFERENCE NOTE}

1. Brown, T. G. Concurrent adjunctive escape and attack behaviors. Paper presented at the annual meeting of the Eastern Psychological Association, Boston, 1977.

\section{REFERENCES}

Ator, N. A. Mirror pecking and timeout under a multiple fixedratio schedule of food delivery. Journal of the Experimental Analysis of Behavior, 1980, 34, 319-328.

Azrin, N. H. Time-out from positive reinforcement. Science, 1961, 133, 382-383.

Azrin, N. H., Hutchinson, R. R., \& Hake, D. F. Extinctioninduced aggression. Journal of the Experimental Analysis of Behavior, 1966, 9, 191-204.

Brown, T. G., \& Flory, R. K. Schedule-induced escape from fixed-interval reinforcement. Journal of the Experimental Analysis of Behavior, 1972, 17, 395-403.

Cohen, P. S., \& Looney, T. A. Schedule-induced mirror responding in the pigeon. Journal of the Experimental Analysis of Behavior, 1973, 19, 395-408.

Coughlin, R. C., JR. The aversive properties of withdrawing positive reinforcement: A review of the recent literature. Psychological Record, 1972, 22, 333-354.

DEWEESE, J. Schedule-induced biting under fixed-interval schedules of food or electric-shock presentation. Journal of the Experimental Analysis of Behavior, 1977, 27, 419-431.

FLORY, R. K. Attack behavior in a multiple fixed-ratio schedule of reinforcement. Psychonomic Science, 1969, 16, 156-157.

Looney, T. A., \& Cohen, P. S. Aggression induced by intermittent positive reinforcement. Neuroscience and Biobehavioral Reviews, 1982, 6, 15-37.

Looney, T. A., Cohen, P. S., \& Yoburn, B. C. Variables affecting establishment of schedule-induced attack on pictorial targets in White King pigeons. Journal of the Experimental Analysis of Behavior, 1976, 26, 349-360.

Looney, T. A., \& McClure, J. T. A comparison of scheduleinduced attack in White King and White Carneaux pigeons. Bulletin of the Psychonomic Society, 1981, 18, 133-134.

Zimmerman, J., \& Ferster, C. B. Some notes on time out from reinforcement. Journal of the Experimental Analysis of Behavior, 1964, 7, 13-19.

(Received for publication March 13, 1982.) 